Article

\title{
Deacidification of Palm Oil Using Betaine Monohydrate-Carboxylic Acid Deep Eutectic Solvents: Combined Extraction and Simple Solvent Recovery
}

\author{
Kamarza Mulia ${ }^{1, *(\mathbb{D})}$, Mohammad Nasikin ${ }^{1} \mathbb{D}$, Elsa Anisa Krisanti ${ }^{1}\left(\mathbb{D}\right.$ and Ida Zahrina ${ }^{2, *}$ \\ 1 Department of Chemical Engineering, Universitas Indonesia, Depok 16424, Indonesia; \\ mnasikin@che.ui.ac.id (M.N.); elsakm@che.ui.ac.id (E.A.K.) \\ 2 Department of Chemical Engineering, University of Riau, Pekanbaru 28293, Indonesia \\ * Correspondence: kmulia@che.ui.ac.id (K.M.); ida.zahrina@lecturer.unri.ac.id (I.Z.)
}

Received: 5 January 2020; Accepted: 2 May 2020; Published: 7 May 2020

check for updates

\begin{abstract}
Steam stripping is commonly used to remove free fatty acids from crude palm oil. An alternative deacidification method, solvent extraction performed at a much lower temperature, would preserve the natural antioxidants in the refined palm oil. In this work, palmitic acid was extracted using betaine monohydrate-propionic acid and betaine monohydrate-acetic acid deep eutectic solvents (DESs). The effect of temperature $\left(40{ }^{\circ} \mathrm{C}\right.$ to $\left.80^{\circ} \mathrm{C}\right)$, mass ratio of palm oil to solvent ( $2: 1$ to $1: 2)$, and palmitic acid content in the palm oil feed ( $2 \%$ to $8 \%$ mass) on the distribution coefficient values of palmitic acid (0.44-0.93) was investigated. For the first time, a facile recovery of DESs could be accomplished by a cooling process where up to $98 \%$ of the palmitic acid separates as solid. A solvent extraction process for palm oil deacidification, employing a DES with a distribution coefficient value much higher than unity, will provide advantages over the steam stripping process.
\end{abstract}

Keywords: deacidification; palm oil; deep eutectic solvent; solvent recovery; liquid-liquid extraction; betaine monohydrate

\section{Introduction}

In the palm oil industry, steam stripping is a common deacidification method used to remove undesirable materials such as free fatty acids, mainly palmitic acid $(41 \%-47 \%)$ and oleic acid $(36 \%-41 \%)$ [1]. The presence of free fatty acids in palm oil indicates that degradation has occurred. As free fatty acids are susceptible to autoxidation, affecting the organoleptic qualities of the oil, palm oil is refined to obtain a stable product for consumption [2]. Due to the high temperature of the steam, natural antioxidants are lost where $\alpha$-carotene and $\beta$-carotene $(500-700 \mathrm{mg} / \mathrm{kg}$ ) are lost completely, while tocopherols (600-1000 mg/ $/ \mathrm{kg}$ ) are partially steam-stripped to $356-630 \mathrm{mg} / \mathrm{kg}$ [3]. Moreover, as palm oil lipids are exposed to temperatures higher than $200{ }^{\circ} \mathrm{C}$, carcinogenic byproducts such as 3-monochloropropane-1,2-diol (3-MCPD) and glycidyl esters are also formed [4,5]. In a steam deacidification optimization study, the final oil acidity was found to be dependent on temperature, percent of stripping steam, and composition of the model palm oil [6]. Other deacidification methods have also been investigated, including esterification reaction of the free fatty acid with methanol catalyzed by an acid ion exchange resin [7], and with glycerol catalyzed by a lipase enzyme [8].

Liquid-liquid extraction performed at temperatures close to ambient temperature would prevent the formation of undesired side reaction products, preserving the natural antioxidants in the crude palm oil. It is known from previous palm oil deacidification studies that anhydrous ethanol extracts more free fatty acids compared to hydrated ethanol $[9,10]$. The use of hydrated ethanol $(6 \%$ weight of water) preserved up to $99 \%$ of the carotenes and up to $80 \%$ of the tocopherols in the refined palm oil [11]. 
More recently, deep eutectic solvents (DESs) have been used in solvent extraction processes due to their desirable characteristics in terms of biodegradability, biocompatibility, and green designer solvent [12]. A DES consists of a hydrogen bond acceptor (HBA) that form hydrogen bonds with one or more hydrogen bond donor (HBD), and thus, has a lower melting point than those of its constituents. Choline chloride $(\mathrm{ChCl})$-based DESs with organic acids (acetic, propionic, lactic, malic, oxalic, citric, malonic or phenylacetic acids) as HBDs have been successfully applied as green solvents for extraction of natural compounds from plants [13-16]. Betaine-based DESs have not been studied as intensively as ChCl-based DESs, in spite of the fact that betaine is also a generally recognized as safe chemical.

We evaluated betaine monohydrate-based DESs, with a polyol or a mixture of polyol-acid HBDs as extracting solvents, in the deacidification of palm oil by liquid-liquid extraction [17]. Palmitic acid, as a free fatty acid with the highest concentration in palm oil [1], was chosen as a model compound. The study revealed that the betaine monohydrate-glycerol DES (1:8 molar ratio) gave the highest selectivity with up to $99 \%$ of the $\beta$-carotene and $\alpha$-tocopherol retained in the palm oil phase, and, the palmitic acid distribution coefficient of 0.52 . The follow-up study [18] revealed the presence of strong interactions between the oxygen atom of betaine molecules and hydrogen atoms of glycerol in the betaine monohydrate-glycerol DES. The intramolecular interactions in the glycerol molecules and the interaction between glycerol and water molecule in the betaine monohydrate were present at higher concentration of glycerol in the DES. At this condition, the interaction between palmitic acid and betaine molecules decreases due to the presence of interaction between palmitic acid and glycerol. Based on their fusion enthalpy values, the calculated total interaction energy of the betaine monohydrate-carboxylic acid (acetic and propionic) DESs [19] were found to be lower than that of the betaine monohydrate-glycerol eutectic DES (molar ratio of 1:2) [20]. This finding suggests that palmitic acid, having a carboxylic functional group, would have a high probability of interaction with the betaine monohydrate-carboxylic acid DESs.

On the other hand, the nonpolar long-chains of the carotene and tocopherol would have a very low probability to interact with this DES molecule. The solubilities of the antioxidants in a more polar solvent, such as an acid-based DES will be lower than that in a less polar solvent, such as a polyol-based DES. For instance, anthocyanins that are polar molecules have higher extraction efficiency in the choline chloride-oxalic acid DES than those the choline chloride-glycerol DES [14]. It is necessary to recover the solvent for reuse due to health, safety, cost, and environmental considerations [21]. In the deacidification of rice bran oil, ethanol was recovered by cooling the liquid stream leaving the extractor. The theoretical study revealed that solvent recovery by the cooling process is feasible, reaching up to $98 \%$ of the oil, when the stream is cooled from $80^{\circ} \mathrm{C}$ to $25^{\circ} \mathrm{C}$ [22].

In this study, we investigated the two following aspects of betaine monohydrate-carboxylic acid (propionic or acetic acid) DESs as the extracting solvents for separation of palmitic acid from palm oil: (i) the effect of the process conditions (temperature, mass ratio of palm oil to solvent, and palmitic acid content in palm oil) on the distribution coefficient and extraction efficiency of palmitic acid, (ii) the effect of temperature and duration of cooling on the extent of palmitic acid separated from DESs as a solid. It was anticipated that this work would provide direction for further research, that is, which aspect needs more attention in order to improve the feasibility of using DESs for palm oil deacidification.

\section{Materials and Methods}

\subsection{Chemicals}

Synthesis grade acetic acid (glacial) and propionic acid (purity 99\%) were supplied by Merck (Singapore). Analytical grade (purity 99\%) betaine monohydrate, palmitic acid, $\beta$-carotene, and $\alpha$-tocopherol were supplied by Sigma Aldrich (Singapore). Analytical grade $\alpha$-tocopherol (purity $99.9 \%$ ) and $\beta$-carotene (purity 99\%), used as standards in the preparation of calibration curves, were supplied by Sigma Aldrich. HPLC grade (purity 99.9\%) tetrahydrofuran, acetonitrile, acetic acid glacial, and methanol were supplied by Merck. Analytical grade diethyl ether, chloroform, methanol, 
ethanol, and phenolphthalein indicator were supplied by Merck. The composition of fatty acids in the analytical grade of palm oil that was purchased from Sigma Aldrich is shown in Table 1.

Table 1. Fatty acid composition of palm oil used in this study.

\begin{tabular}{cc}
\hline Fatty Acid & \% Mass \\
\hline Palmitic (c16:0) & 44.6 \\
Oleic (c18:1) & 38.1 \\
Linoleic (c18:2) & 9.5 \\
Stearic (c18:0) & 4.3 \\
Myristic (c14:0) & 1.0 \\
\hline
\end{tabular}

\subsection{Preparation of DESs and Palm Oil}

DESs consisting of betaine monohydrate and carboxylic acid were prepared following the procedure given in the previous work [19]. Betaine monohydrate was dried by vacuum drying at a temperature of $80{ }^{\circ} \mathrm{C}$ for $6 \mathrm{~h}$, then, it was mixed with acetic acid or propionic in several mole fractions of acid $(0.67,0.75,0.80,0.86$, and 0.89$)$ by weighing on an analytical balance (Sartorius TE214S). The mixture was placed in a bottle with a screw-cap and a stirring bar, heated at a temperature of $50{ }^{\circ} \mathrm{C}$ on a hotplate stirrer with an agitation speed of $150 \mathrm{rpm}$ for $90 \mathrm{~min}$.

Palm oil used in this work was prepared to have a final composition similar to that of the actual palm oil by the addition of palmitic acid ( $5 \%$ mass), $\alpha$-tocopherol (1000 ppm), and $\beta$-carotene (700 ppm) into the analytical grade palm oil.

\subsection{Liquid-Liquid Extraction}

Palm oil and DES were mixed in a volume ratio of 1:2 and agitated at $250 \mathrm{rpm}$ for $2 \mathrm{~h}$ at a temperature of $40^{\circ} \mathrm{C}$ using a hotplate stirrer (IKA C-MAG HS7, Staufen, Germany). After stirring, the mixture was separated using a centrifuge (Nesco 80-2A, Jiangsu, China), and was left still for at least $60 \mathrm{~min}$ to allow a complete phase separation. The extract (lower) phase was separated from the refined oil (upper) phase using a Hamilton syringe (Reno, NV, USA). The time taken to reach equilibrium was $2 \mathrm{~h}$, determined by sampling the oil phase every $10 \mathrm{~min}$ until the palmitic content of the three consecutive samples was constant [17].

Quantitative analysis of palmitic acid was carried using an alkali titration on the oil phase following the IUPAC official method 2201 [10]. Warm water was used to wash and remove traces of DES in the oil phase until pH of the sample was neutral. The solvent-free oil phase dispensed with a micropipette was accurately quantified by weighing on an analytical balance (2 g), added with two drops of phenolphthalein solution and $25 \mathrm{~mL}$ of solvent consisting of ethyl ether and ethanol in a 2:1 volume ratio. Then, the mixture was titrated with $0.05 \mathrm{M} \mathrm{KOH}$ in ethanol solution until a permanent color change was observed. The amount of palmitic acid in the oil phase was determined and the difference with the initial amount was calculated as the amount of acid in the solvent phase. The analysis was carried out in triplicates.

The quantity of antioxidants ( $\beta$-carotene and $\alpha$-tocopherol) extracted into DES were determined in triplicates using a high performance liquid chromatography method [23]. These compounds were back-extracted by mixing $0.4 \mathrm{~mL}$ of DES with $2 \mathrm{~mL}$ of organic solvent (chloroform and methanol in a 1:1 volume ratio). The quantity of antioxidants in the organic solvent was measured using an LC-20AD Shimadzu HPLC (Kyoto, Japan) equipped with an SPD-20A UV/VIS detector and a YMC-Triart C8 $(150 \times 4.6 \mathrm{~mm}$ I.D. size $)$ column. The mobile phase A consisted of methanol, water, and acetic acid (750:250:4 volume ratio), while the mobile phase B consisted of acetonitrile, methanol, tetrahydrofuran, and acetic acid (500:375:125:4 volume ratio). The linear gradient of the mobile phase was programmed (in minutes): (0-1) 30-50\% B; (1-5) 50-60\% B; (5-10) 60-65\% B; (10-12) 65-90\% B; (12-17) 90-100\% B; (17-17.1) $100-30 \% \mathrm{~B}$; (17.1-20) 30\% B, at a flow rate of $1.5 \mathrm{~mL} \cdot \mathrm{min}^{-1}$. The injection volume was $10 \mu \mathrm{L}$ 
at a temperature of $40{ }^{\circ} \mathrm{C}$. The chromatograms of $\alpha$-tocopherol and $\beta$-carotene were recorded at 300 and $450 \mathrm{~nm}$, respectively.

To evaluate the effect of extraction process condition, palm oil containing various palmitic acid contents ( $2 \%, 5 \%, 8 \%$ mass) was mixed with betaine monohydrate-propionic acid DES (mole fraction of acid of 0.89$)$ in different mass ratios of oil to solvent $(1: 1,1: 2,2: 1)$ and various temperatures $\left(40{ }^{\circ} \mathrm{C}\right.$, $60^{\circ} \mathrm{C}, 80^{\circ} \mathrm{C}$ ). The mixture was agitated at $250 \mathrm{rpm}$ for $2 \mathrm{~h}$ using a hotplate stirrer (IKA C-MAG HS7, Staufen, Germany). It was expected that the antioxidants present in the palm oil would not degrade to a significant extent during the extraction carried out at $80^{\circ} \mathrm{C}$ for $2 \mathrm{~h}$. For instance, no significant degradation $(<5 \%)$ was observed when $\alpha$-tocopherol was dissolved in rice bran oil at $100{ }^{\circ} \mathrm{C}$ for $2 \mathrm{~h}$ [24], while, no degradation was observed for $\beta$-carotene dissolved in pure olive oil at temperatures below $115^{\circ} \mathrm{C}[25]$.

The distribution coefficient of a solute $i$ (palmitic acid, $\alpha$-tocopherol, or $\beta$-carotene) in the deacidification of palm oil by liquid-liquid extraction, employing betaine monohydrate-carboxylic acid DESs as the extracting solvents, was calculated using Equation (1):

$$
\text { Distribution coefficient }(i)=\frac{C_{i}^{D E S}}{C_{i}^{\text {Palm Oil }}}
$$

where $C_{i}^{D E S}$ and $C_{i}^{\text {Palm Oil }}$ represent the solute concentration in the DES (or extract) phase and palm oil (or raffinate) phase, respectively. The selectivity of solvent was calculated using Equation (2), where $k_{1}, k_{2}, k_{3}$ are the distribution coefficients of palmitic acid, $\alpha$-tocopherol, and $\beta$-carotene, respectively:

$$
\text { Selectivity }=\frac{k_{1}}{k_{2}+k_{3}}
$$

In addition, the extraction efficiency of palmitic acid was calculated using Equation (3):

$$
\text { Extraction efficiency }(\%)=100 \times \frac{C_{P A}^{D E S}}{C_{P A}^{\text {Palm oil, feed }}}
$$

where $C_{P A}^{D E S}$ and $C_{P A}^{\text {Palm oil, feed }}$ represent the concentrations of the palmitic acid extracted into the DES-rich phase and present in the feed palm oil, respectively.

\subsection{FT-IR and NMR Investigation of Oil-Rich and DES-Rich Phases}

Fourier transform infrared (FT-IR) spectroscopy and nuclear magnetic resonance (NMR) were used to investigate the palm oil, DES-rich phase, and oil-rich phase for the possibility of transfer of compounds between phases and for chemical degradation during extraction. The DES used was the betaine monohydrate-propionic acid (mole fraction of acid of 0.89). A Perkin Elmer UATR Two spectrometer (Waltham, MA, USA) was used to record the infrared spectra in the frequency range of 4000 to $400 \mathrm{~cm}^{-1}$, and a JEOL JNMECA 500 NMR spectrometer (Tokyo, Japan) was used to record the ${ }^{1} \mathrm{H}-\mathrm{NMR}$ spectra of these liquids diluted in chloroform [17].

\subsection{Solvent Recovery}

Solvent recovery was performed by a simple cooling of the extract phase, betaine monohydratepropionic acid DES with acid mole fraction of 0.89 , at different temperatures $\left(21^{\circ} \mathrm{C}, 18{ }^{\circ} \mathrm{C}, 15^{\circ} \mathrm{C}\right)$ for various times ( 2 to $22 \mathrm{~h}$ ). The palmitic acid solid was separated using a vacuum filter and the quantity of palmitic acid in the solvent after cooling was determined by a Shimadzu GC-2014 gas chromatograph (Kyoto, Japan) equipped with an RTX-1 column (length of $25 \mathrm{~m}$, ID of $0.25 \mathrm{~mm}$ ) and a flame ionization detector. The temperature program of the GC was set to start at $40{ }^{\circ} \mathrm{C}$ followed by an immediate ramping at a rate of $5^{\circ} \mathrm{C} \cdot \mathrm{min}^{-1}$ until the temperature reaches $250{ }^{\circ} \mathrm{C}$. The carrier gas used 
was helium at a pressure of $100 \mathrm{kPa}$. The amount of solid palmitic acid separated from the extract phase due to cooling was calculated using Equation (4):

$$
\text { Separated palmitic acid }(\%)=\frac{C_{P A}^{D E S, \text { initial }}-C_{P A}^{D E S, \text { after cooling }}}{C_{P A}^{D E S, \text { initial }}} \times 100
$$

where $C_{P A}^{D E S \text {, initial }}$ and $C_{P A}^{a f t e r}$ cooling represent the concentration of palmitic acid in the DES-rich phase before and after the cooling process, respectively.

\section{Results and Discussion}

\subsection{Betaine Monohydrate-Carboxylic Acid DES as a Solvent for Deacidification of Palm Oil}

The distribution coefficient values obtained using the betaine monohydrate-propionic acid and betaine monohydrate-acetic acid DESs as a function of the mole fraction of acid are shown in Figure 1a,b, respectively. Figure 1a shows that distribution coefficients of palmitic acid increases with increasing propionic acid mole fraction, reached a maximum, and then decreased. Peng et al. reported extraction yields obtained using $\mathrm{ChCl}$-alcohol DESs on the extraction of phenolic acids from plant [26], similar to the plots shown in Figure 1a. In contrast, Figure $1 \mathrm{~b}$ shows a reverse trend obtained using betaine monohydrate-acetic acid DES. The effect of the mole fraction of the acids on the distribution coefficients of palmitic acid follows no certain trend, which probably relates to the complex hydrogen bonding interactions between DES and solutes.
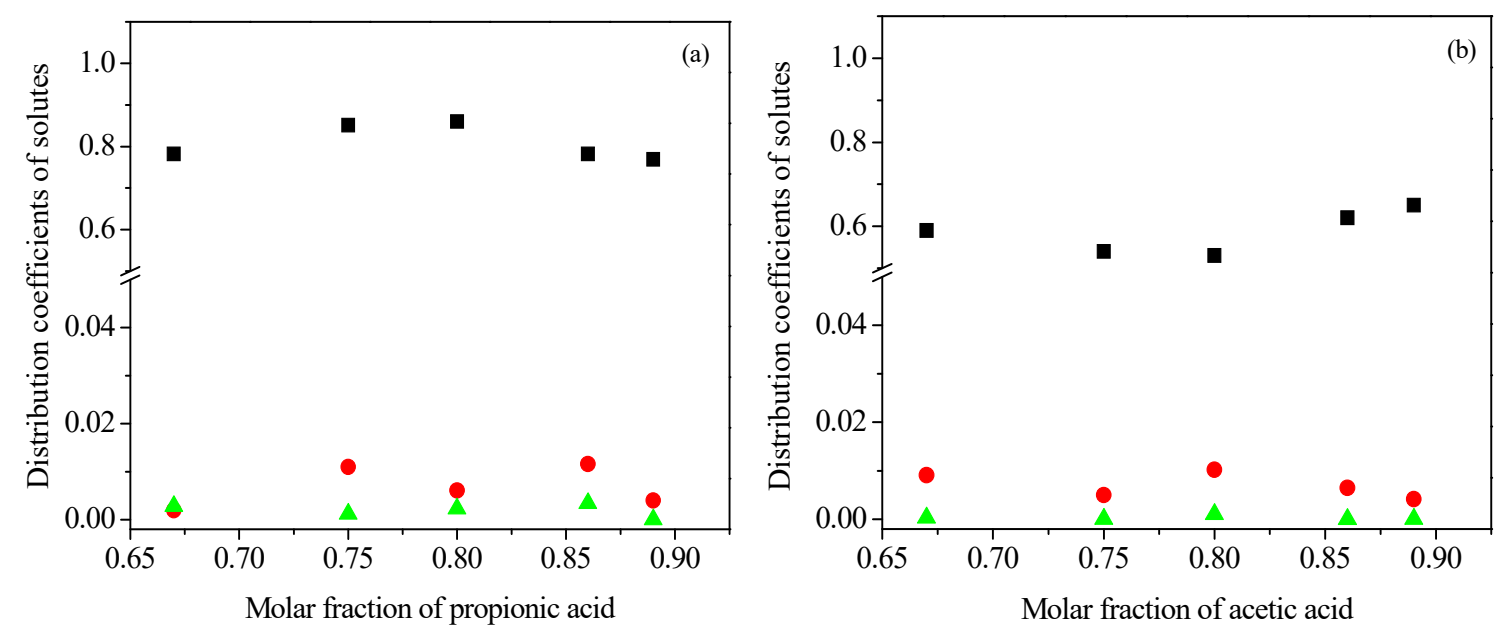

Figure 1. Distribution coefficients of solutes using betaine monohydrate-propionic deep eutectic solvents (DES) (a) and betaine monohydrate-acetic acid DES $(\mathbf{b}) ;(\mathbf{a})$ palmitic acid, $(\triangle) \beta$-carotene, $(\bullet)$ $\alpha$-tocopherol, volume ratio of oil to solvent of $1: 2$, and temperature of $40{ }^{\circ} \mathrm{C}$ for $2 \mathrm{~h}$.

The higher distribution coefficient values of the propionic acid DESs (0.77-0.86) compared to those of the acetic acid DESs (0.53-0.65) could be explained by the similarity between the polarity of DES used as the extracting solvent and the polarity of palmitic acid. Propionic acid DES is less polar than acetic acid DES at the same acid mole fraction, and therefore, a better solvent for extracting palmitic acid from palm oil. A similar trend was observed in the extraction of saponin where the yield of extraction using ChCl-propionic acid DES is less than that of $\mathrm{ChCl}$-acetic acid DES due to the more polar nature of saponin [13]. Additionally, Bubalo et al. [14] and Garcia et al. [15] reported higher extraction efficiencies of more polar compounds from grape skin and virgin olive oil, respectively, using more polar DESs.

The highest distribution coefficient value of palmitic acid shown in Figure 1a is comparable to those reported previously ( 0.97 and 0.74$)$, obtained using betaine monohydrate-propylene glycol [17] 
and betaine-1,2-butanediol [27] DESs, respectively. It is desirable for this ratio of the concentration of palmitic acid in the extract and raffinate phases to be much larger than unity, to reduce the amount of solvent required in the deacidification process. Therefore, it is recommended to focus upcoming research on finding suitable DESs, most likely among those less polar than betaine-based or choline chloride-based DESs.

As can be seen in Figure 2a, betaine monohydrate-propionic acid DES at a molar fraction of acid of 0.89 shows the highest selectivity of palmitic acid to antioxidant compounds. This value is lower than those of betaine monohydrate-glycerol DES (molar ratio of 1:8) and betaine monohydrate-glycerol-propionic acid (molar ratio of 1:1:1), and yet, higher than those of the other DESs investigated in the previous work [17]. The selectivities obtained indicate that most of the antioxidants remained in the palm oil, regardless of the DES used. Figure $2 b$ shows the extraction efficiency values plotted against acid mole fraction, where the highest extraction efficiency of $46.2 \%$ was obtained using the betaine-propionic acid DES, $11.7 \%$ higher than that of the betaine-acetic acid DES at the same acid mole fraction of 0.8 .
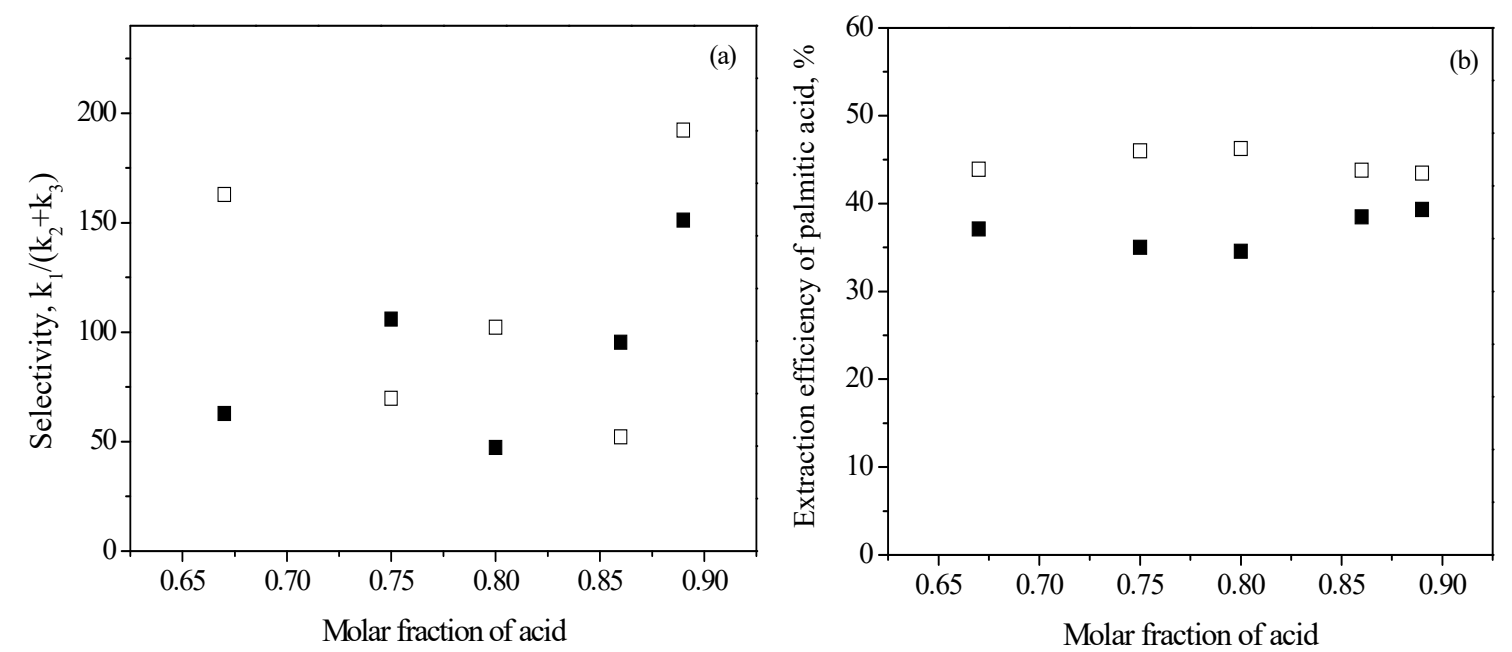

Figure 2. Selectivity of DESs (a) and extraction efficiency of palmitic acid (b); betaine monohydrate-propionic acid DESs ( $\square$ ) and betaine monohydrate-acetic acid DESs ( $\square$ ), volume ratio of oil to solvent of $1: 2$, temperature of $40^{\circ} \mathrm{C}$, agitation at $250 \mathrm{rpm}$ for $2 \mathrm{~h}$.

\subsection{Effect of Extraction Conditions on the Distribution Coefficients of Palmitic Acid}

The effect of extraction conditions (temperature, mass ratio of palm oil to solvent, and palmitic acid content in the palm oil feed) on the distribution coefficient of palmitic acid, evaluated using betaine monohydrate-propionic acid DES (mole fraction of 0.89), is shown in Figure 3. It can be seen that higher values of the distribution coefficient of palmitic acid were obtained as the palm oil to solvent mass ratios were decreased. In this case, the addition of more solvent facilitates interaction between the hydroxyl group of palmitic acid and the carboxylic group of betaine. Similar results have been observed in previous works, where a lower oil to solvent mass ratio provided a better transfer of the free fatty acids to the alcoholic phase [28,29]. Bi et al. [30] reported that flavonoids and polyalcohols compete to interact with the chloride anion of choline chloride during extraction process using polyalcohol-based DESs as solvent.

The temperature greatly influences the distribution coefficient of palmitic acid only for the mass ratio of oil to solvent of 1:2. In this case, the increase in temperature seems to induce a solubility increase in the solvent. Similar results also reported by da Silva et al. [10] that the increase in temperature enhances the distribution coefficient of free fatty acid due to the increase of mutual solubility of the oil and solvent. Furthermore, the viscosity of the solvent decreases at higher temperatures, which improved the diffusion and mass transfer. 

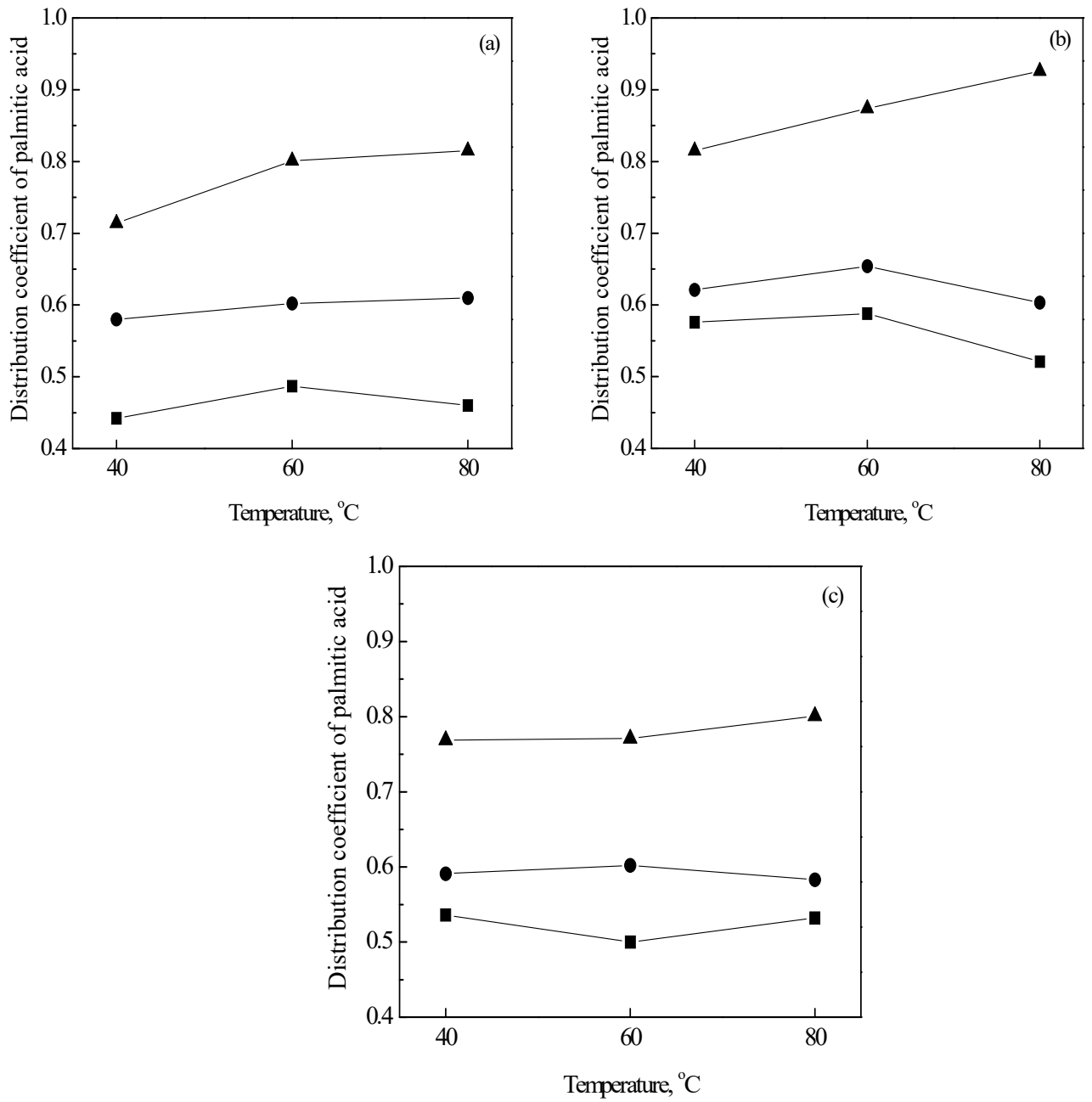

Figure 3. Distribution coefficient of palmitic acid as a function of temperature, palm oil to solvent mass

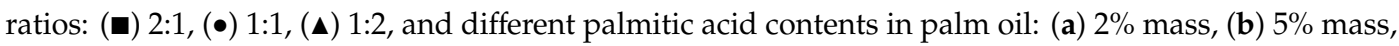
(c) $8 \%$ mass.

Figure 3 also shows increasing and decreasing values of the distribution coefficient of palmitic acid as the palmitic acid content in palm oil was increased from $2 \%$ to $8 \%$ mass. The observed effect of extraction conditions on the distribution coefficients of palmitic acid is consistent with the ANOVA results of the central composite design experiment of a similar deacidification study using a betaine monohydrate-propionic acid DES. It was found that the effect of the oil to solvent mass ratio and the palmitic content in palm oil were statistically significant $(p<0.05)$, while the effect of temperature was not significant [31].

\subsection{FT-IR and NMR Analysis of Oil-Rich and DES-Rich Phases}

The FT-IR and ${ }^{1} \mathrm{H}-\mathrm{NMR}$ spectra of the DES-rich phase (a), oil-rich phase (b), and palm oil before extraction (c), are shown in Figures 4 and 5, respectively. Figure 4a shows two absorption peaks of propionic acid in the infrared spectrum of the DES-rich phase due to the carbonyl $\mathrm{C}=\mathrm{O}$ stretching $\left(1707 \mathrm{~cm}^{-1}\right)$ and the $\mathrm{C}-\mathrm{O}$ stretching $\left(1241 \mathrm{~cm}^{-1}\right)$ in the fingerprint region [32]. These two peaks are also present in the spectrum of the oil-rich phase, as displayed in Figure $4 \mathrm{~b}$. Similarly, Figure $5 c$ shows two NMR resonance peaks present in the DES-rich phase with chemical shifts around 1.1 and 2.3 ppm due to the methyl and methylene functional groups of propionic acid, respectively [33]. The FT-IR and NMR spectra show peaks that belong to propionic acid, the main component of the DES-rich phase present in the oil-rich phase, but not in the palm oil before extraction. This spectra analysis indicates 
that propionic acid is partly soluble in the oil-rich (raffinate) phase. There is no indication that betaine is transferred to the oil-rich phase.

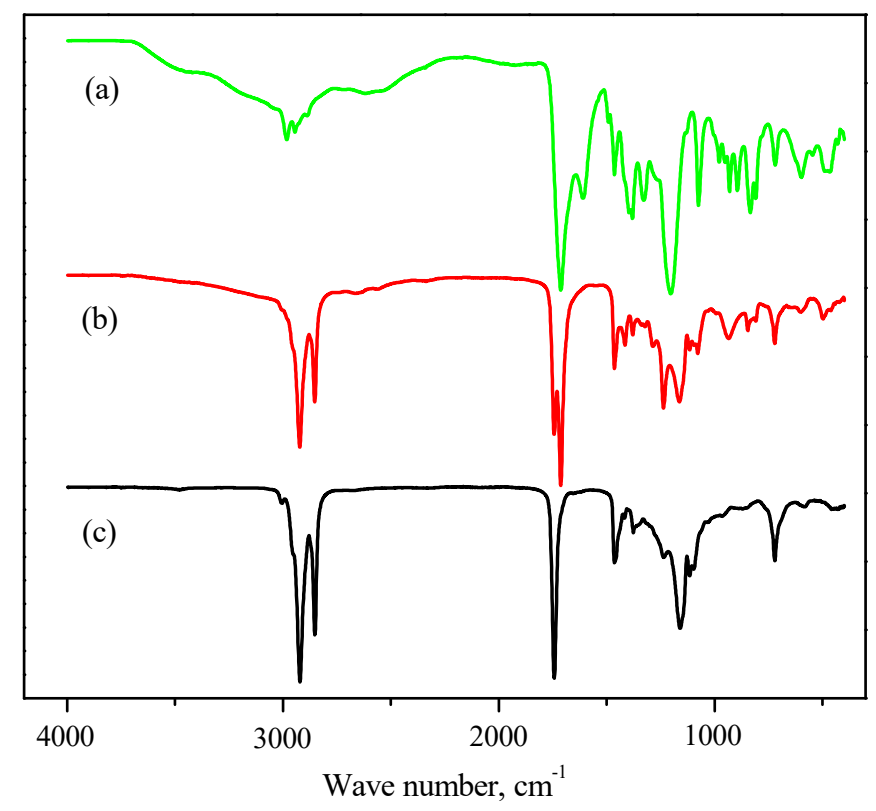

Figure 4. Infrared spectra of DES-rich phase (a), oil-rich phase (b), and palm oil before extraction (c); DES: betaine monohydrate-propionic acid with a mole fraction of acid of 0.89 .

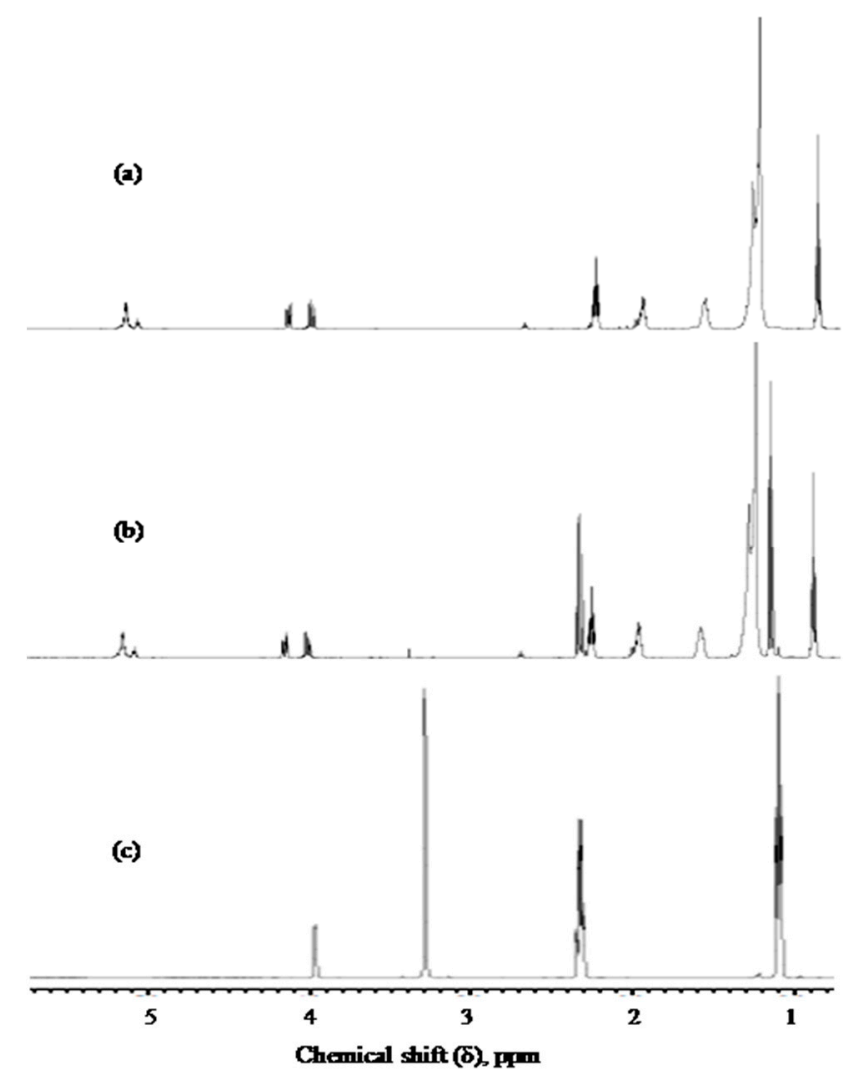

Figure 5. ${ }^{1} \mathrm{H}-\mathrm{NMR}$ spectra of palm oil before extraction (a), oil-rich phase (b), and DES-rich phase (c); DES: betaine monohydrate-propionic acid with a mole fraction of acid of 0.89 .

The transfer of either HBA or HBD of the DES to the palm-oil rich phase is not desirable because of solvent loss and the possibility of contamination of palm oil. Transfer of the HBD to the oil-rich 
phase was not observed in a similar deacidification system employing betaine-monohydrate-glycerol DES [17]. The NMR spectra did not show any unidentified peak, suggesting that both propionic acid and palmitic acid were stable during the extraction process. Flavonoids (luteolin and apigenin) extracted from virgin olive oil were stable at the extreme $\mathrm{pH}$ of $\mathrm{ChCl}$-acid (lactic or malonic acid) DES as the solvents [15]. Also, palm oil compounds were stable during the deacidification of palm oil using betaine monohydrate-glycerol DES as a solvent [17].

\subsection{Solvent Recovery by Cooling the DES-Rich Phase to Solidify Palmitic Acid}

Solvent recovery is an important part of a large-scale extraction process. Figure 6 shows that the percentage of palmitic acid separated depends on the duration and temperature of the cooling process. Cooling the DES-rich phase to $18{ }^{\circ} \mathrm{C}$ gives the best cooling curve, where palmitic acid could be almost completely separated from the extract phase as a solid (up to $98 \%$ ). At a higher cooling temperature of $21^{\circ} \mathrm{C}$, solidification rate is lower than it is at $18^{\circ} \mathrm{C}$ because of the small temperature driving force. On the other hand, a high solidification rate at $15^{\circ} \mathrm{C}$ is observed only in the beginning, followed by a negligible solidification as indicated by the flat cooling curve. This might be due to the increased viscosity of the DES at the lowest cooling temperature that hinders further diffusion of solutes, causing a decreased degree of formation of palmitic acid solids. Oliveira et al. [22] reported that the decrease in cooling temperature resulted in decreased solubility of palmitic acid in ethanol.

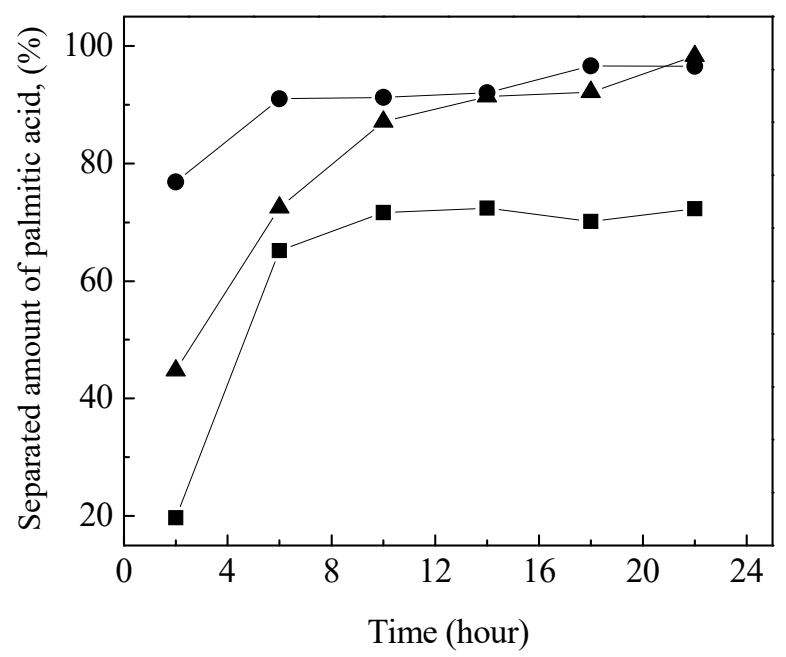

Figure 6. Separated palmitic acid as a function of cooling time and temperature: $(\boldsymbol{\square}) 15^{\circ} \mathrm{C},(\bullet) 18^{\circ} \mathrm{C}$, (4) $21^{\circ} \mathrm{C}$.

\section{Conclusions}

This study shows the advantages of using DESs to separate palmitic acid from palm oil, as no byproducts are formed, and the antioxidants practically remained in the palm oil. The distribution coefficient values of palmitic acid obtained using betaine-monohydrate propionic acid and betaine-monohydrate acetic acid DESs were less than unity, comparable to those of the betaine monohydrate-polyol and betaine-polyol DESs reported earlier. On the other hand, and for the first time, it is shown that a facile DES recovery could be accomplished by cooling the extract phase, separating up to $98 \%$ of the palmitic acid as solid. Further research that focus on finding DESs with distribution coefficients values much higher than unity is recommended, as if it is achieved, the combined extraction and solvent recovery steps could provide real advantages over the steam stripping process for the deacidification of palmitic acid. 
Author Contributions: K.M., M.N., E.A.K., and I.Z.; conceptualization, K.M., M.N., I.Z.; formal analysis, K.M., E.A.K., I.Z.; data curation, I.Z.; funding acquisition, K.M., I.Z.; investigation, K.M., M.N., E.A.K., I.Z.; methodology, K.M., I.Z.; project administration, I.Z.; supervision, K.M., M.N., E.A.K.; writing—original draft, I.Z.; writing-review and editing, K.M. All authors have read and agreed to the published version of the manuscript.

Funding: This research was funded by the Indonesian Ministry of Research, Technology and Higher Education, Penelitian Dasar scheme contract number NKB-1780/UN2.R3.1/HKP.05.00/2019.

Conflicts of Interest: The authors declare no conflict of interest.

\section{References}

1. Gee, P.T. Analytical characteristics of crude and refined palm oil and fractions. Eur. J. Lipid Sci. Technol. 2007, 109, 373-379. [CrossRef]

2. Shahidi, F. Bailey's Industrial Oil and Fat Products; Wiley Interscience: Hoboken, NJ, USA, 2005; Volume 2, pp. 333-429.

3. Goh, S.; Choo, Y.; Ong, S. Minor constituents of palm oil. J. Am. Oil Chem. Soc. 1985, 62, 237-240. [CrossRef]

4. Craft, B.D.; Nagy, K.; Seefelder, W.; Dubois, M.; Destaillats, F. Glycidyl esters in refined palm (Elaeis guineensis) oil and related fractions. Part II: Practical recommendations for effective mitigation. Food Chem. 2012, 132, 73-79. [CrossRef]

5. Ermacora, A.; Hrncirik, K. Influence of oil composition on the formation of fatty acid esters of 2-chloropropane-1,3-diol (2-MCPD) and 3-chloropropane-1,2-diol (3-MCPD) under conditions simulating oil refining. Food Chem. 2014, 161, 383-389. [CrossRef]

6. Sampaio, K.A.; Ceriani, R.; Silva, S.M.; Taham, T.; Meirelles, A.J. Steam deacidification of palm oil. Food Bioprod. Process. 2011, 89, 383-390. [CrossRef]

7. Pirola, C.; Galli, F.; Comazzi, A.; Manenti, F.; Bianchi, C. Preservation of carotenes in the deacidification of crude palm oil. RSC Adv. 2014, 4, 46922-46925. [CrossRef]

8. Kumar, P.P.; Krishna, A.G. Effect of different deacidification methods on phytonutrients retention in deacidified fractionated palm oil. J. Am. Oil Chem. Soc. 2015, 92, 645-658. [CrossRef]

9. Gonçalves, C.B.; Meirelles, A.J.A. Liquid-liquid equilibrium data for the system palm oil + fatty acids + ethanol + water at 318.2K. Fluid Phase Equilib. 2004, 221, 139-150.

10. Da Silva, A.E.; Lanza, M.; Batista, E.A.; Rodrigues, A.M.; Meirelles, A.J.; da Silva, L.H.M. Liquid-Liquid Equilibrium Data for Systems Containing Palm Oil Fractions+Fatty Acids + Ethanol + Water. J. Chem. Eng. Data 2011, 56, 1892-1898. [CrossRef]

11. Gonçalves, C.B.; Filho, P.A.P.; Meirelles, A.J. Partition of nutraceutical compounds in deacidification of palm oil by solvent extraction. J. Food Eng. 2007, 81, 21-26. [CrossRef]

12. Wazeer, I.; Hayyan, M.; Hadj-Kali, M.K. Deep eutectic solvents: Designer fluids for chemical processes. J. Chem. Technol. Biotechnol. 2018, 93, 945-958. [CrossRef]

13. Ribeiro, B.D.; Coelho, M.A.Z.; Marrucho, I.M. Extraction of saponins from sisal (Agave sisalana) and juá (Ziziphus joazeiro) with cholinium-based ionic liquids and deep eutectic solvents. Eur. Food Res. Technol. 2013, 237, 965-975. [CrossRef]

14. Bubalo, M.C.; Ćurko, N.; Tomašević, M.; Ganić, K.K.; Redovniković, I.R. Green extraction of grape skin phenolics by using deep eutectic solvents. Food Chem. 2016, 200, 159-166. [CrossRef] [PubMed]

15. García, A.; Rodríguez-Juan, E.; Rodríguez-Gutiérrez, G.; Rios, J.J.; Fernández-Bolaños, J. Extraction of phenolic compounds from virgin olive oil by deep eutectic solvents (DESs). Food Chem. 2016, 197, 554-561. [CrossRef]

16. Radosevic, K.; Curko, N.; Srcek, V.G.; Bubalo, M.C.; Tomasevic, M.; Ganic, K.K.; Redovnikovic, I.R. Natural deep eutectic solvents as beneficial extractants for enhancement of plant extracts bioactivity. LWT Food Sci. Technol. 2016, 73, 45-51. [CrossRef]

17. Zahrina, I.; Nasikin, M.; Krisanti, E.; Mulia, K. Deacidification of palm oil using betaine monohydrate-based natural deep eutectic solvents. Food Chem. 2018, 240, 490-495. [CrossRef]

18. Zahrina, I.; Nasikin, M.; Mulia, K.; Prajanto, M.; Yanuar, A. Molecular interactions between betaine monohydrate-glycerol deep eutectic solvents and palmitic acid: Computational and experimental studies. J. Mol. Liq. 2018, 251, 28-34. [CrossRef] 
19. Zahrina, I.; Nasikin, M.; Mulia, K. Evaluation of the interaction between molecules during betaine monohydrate-organic acid deep eutectic mixture formation. J. Mol. Liq. 2017, 225, 446-450. [CrossRef]

20. Zahrina, I.; Mulia, K.; Yanuar, A.; Nasikin, M. Molecular interactions in the betaine monohydrate-polyol deep eutectic solvents: Experimental and computational studies. J. Mol. Struct. 2018, 1158, 133-138. [CrossRef]

21. Chemat, F.; Vian, M.A.; Cravotto, G. Green extraction of natural products: Concept and principles. Int. J. Mol. Sci. 2012, 13, 8615-8627. [CrossRef]

22. Oliveira, C.M.; Garavazo, B.R.; Rodrigues, C.E. Liquid-liquid equilibria for systems composed of rice bran oil and alcohol-rich solvents: Application to extraction and deacidification of oil. J. Food Eng. 2012, 110, 418-427. [CrossRef]

23. Plante, M.; Bailey, B.; Acworth, I.; Clark, D. Analysis of Lipids by HPLC-CAD; ESA-Dionex Inc.: Sunnyvale, CA, USA, 2011.

24. Bruscatto, M.; Zambiazi, R.; Sganzerla, M.; Pestana, V.; Otero, D.; Lima, R.; Paiva, F. Degradation of tocopherols in rice bran oil submitted to heating at different temperatures. J. Chromatogr. Sci. 2009, 47, 762-765. [CrossRef] [PubMed]

25. Knockaert, G.; Pulissery, S.K.; Lemmens, L.; Van Buggenhout, S.; Hendrickx, M.; Van Loey, A. Carrot $\beta$-Carotene Degradation and Isomerization Kinetics during Thermal Processing in the Presence of Oil. J. Agric. Food Chem. 2012, 60, 10312-10319. [CrossRef]

26. Peng, X.; Duan, M.H.; Yao, X.H.; Zhang, Y.H.; Zhao, C.J.; Zu, Y.G.; Fu, Y.J. Green extraction of five target phenolic acids from Lonicerae japonicae Flos with deep eutectic solvent. Sep. Purif. Technol. 2016, 157, 249-257. [CrossRef]

27. Mulia, K.; Adam, D.; Zahrina, I.; Krisanti, E. Green extraction of palmitic acid from palm oil using betaine-based Natural Deep Eutectic Solvents. Int. J. Technol. 2018, 9, 335-344. [CrossRef]

28. Rodrigues, C.E.; Onoyama, M.M.; Meirelles, A.J. Optimization of the rice bran oil deacidification process by liquid-liquid extraction. J. Food Eng. 2006, 73, 370-378. [CrossRef]

29. Gonçalves, C.B.; Rodrigues, C.E.; Marcon, E.C.; Meirelles, A.J. Deacidification of palm oil by solvent extraction. Sep. Purif. Technol. 2016, 160, 106-111. [CrossRef]

30. Bi, W.; Tian, M.; Row, K.H. Evaluation of alcohol-based deep eutectic solvent in extraction and determination of flavonoids with response surface methodology optimization. J. Chromatogr. A 2013, 1285, 22-30. [CrossRef]

31. Israyandi; Zahrina, I.; Mulia, K. Optimization process condition for deacidification of palm oil by liquid-liquid extraction using NADES (Natural Deep Eutectic Solvent). AIP Conf. Proc. 2017, 1823, 020107.

32. Koca, N.; Rodriguez-Saona, L.; Harper, W.; Alvarez, V. Application of Fourier transform infrared spectroscopy for monitoring short-chain free fatty acids in Swiss cheese. J. Dairy Sci. 2007, 90, 3596-3603. [CrossRef]

33. SDBSWeb. National Institute of Advanced Industrial Science and Technology. Available online: http: //riodb01.ibase.aist.go.jp/sdbs/ (accessed on 30 April 2020). 